This is a self-archived version of an original article. This version may differ from the original in pagination and typographic details.

Author(s): $\begin{aligned} & \text { Hicks, Jamie; Mansikkamäki, Akseli; Vasko, Petra; Goicoechea, Jose M.; Aldridge, } \\ & \text { Simon }\end{aligned}$

Title: ${ }^{\text {A nucleophilic gold complex }}$

Year: 2019

Version: Accepted version (Final draft)

Copyright: @ 2019, Springer Nature

Rights: In Copyright

Rights url: http://rightsstatements.org/page/InC/1.0/?language=en

Please cite the original version:

Hicks, J., Mansikkamäki, A., Vasko, P., Goicoechea, J. M., \& Aldridge, S. (2019). A nucleophilic gold complex. Nature Chemistry, 11(3), 237-241. https://doi.org/10.1038/s41557-018-0198-1 


\title{
A Nucleophilic Gold Complex
}

\author{
Jamie Hicks, ${ }^{1}$ Akseli Mansikkamäki, ${ }^{2}$ Petra Vasko,,${ }^{1,2}$ Jose M. Goicoechea ${ }^{1, *}$ and Simon \\ Aldridge $e^{1, *}$
}

1. Inorganic Chemistry Laboratory, Department of Chemistry, University of Oxford, South Parks Road, Oxford, UK OX1 3QR.

2. Department of Chemistry, Nanoscience Center, University of Jyväskylä, P. O. Box 35, Jyväskylä, Finland FI-40014.

* To whom correspondence should be addressed. E-mail: simon.aldridge @chem.ox.ac.uk (SA) and jose.goicoechea@chem.ox.ac.uk (JMG).

\begin{abstract}
Solid-state auride salts featuring the negatively charged $\mathrm{Au}^{-}$ion are known to be stable in the presence of alkali metal counter-ions. While such electron-rich species might be expected to be nucleophilic (cf. $\mathrm{I}^{-}$), their instability in solution means that this has not been verified experimentally. Here we report the two-coordinate gold complex (NON)AlAuPtBu $3(3, N O N=$ 4,5-bis(2,6-diisopropylanilido)-2,7-di-tert-butyl-9,9-dimethylxanthene) synthesised by the reaction of the potassium aluminyl complex $[\mathrm{K}\{\mathrm{Al}(\mathrm{NON})\}]_{2}$ (1) with ${ }^{\mathrm{t}} \mathrm{Bu} 3 \mathrm{PAuI}$, and which features a strongly polarized bond, $\mathrm{Au}(\delta-)-\mathrm{Al}(\delta+) .3$ has been studied computationally, with QTAIM charge analysis implying a charge at gold (-0.82) which is in line with the relative electronegativities of the two metals ( $\mathrm{Au}: 2.54$; Al: 1.61 on the Pauling scale). Consistently, $\mathbf{3}$ is found to act as an unprecedented nucleophilic source of gold, reacting with
\end{abstract}


diisopropylcarbodiimide and $\mathrm{CO}_{2}$ to give the $\mathrm{Au}-\mathrm{C}$ bonded insertion products $(\mathrm{NON}) \mathrm{Al}\left(\mathrm{X}_{2} \mathrm{C}\right) \mathrm{AuP}^{\mathrm{t} B u} \mathrm{Bu}_{3}\left(\mathrm{X}=\mathrm{N}^{\mathrm{i} P r}, \mathbf{4} ; \mathrm{X}=\mathrm{O}, \mathbf{5}\right)$. 
Transition elements are known to be able to access multiple oxidation states ${ }^{1}$, a property which underpins widespread application in fields such as small molecule activation and catalysis ${ }^{2,3}$. The vast majority of transition metal complexes however, feature cationic metals in positive oxidation states, ligated by neutral or anionic donors ${ }^{1,4}$. Systems featuring formal negative oxidation states, such as the tetracarbonylferrate ${ }^{5}$ or bis(benzene)vanadium ${ }^{6}$ anions are much less common, and usually require strong $\pi$-acceptor ligands, most frequently $\mathrm{CO}^{7}$. In this regard, gold is unique, being the only transition metal to give rise to a stable "naked" monoanion $\left(\mathrm{Au}^{-}\right.$, auride) in the condensed phase ${ }^{8}$. In part, this is due to relativistic effects which contract the $6 \mathrm{~s}$ orbital significantly, resulting in an electron affinity of $2.30 \mathrm{eV}$, the highest of any transition metal ${ }^{9,10}$. This value is more comparable to those of the chalcogens (e.g. S: $2.08 \mathrm{eV}$; Se: $2.02 \mathrm{eV}$ ) than to the lighter group 11 congeners $(\mathrm{Cu}: 1.23 \mathrm{eV} ; \mathrm{Ag} 1.30 \mathrm{eV})^{10}$. The 12-electron auride anion is typically generated by the reduction of metallic gold with alkali metals, to give salts such as CsAu and $\mathrm{RbAu}^{11,12}$; the solution chemistry of these salts, however, is restricted to liquid ammonia ${ }^{13,14}$. Reduction of organometallic gold compounds to give systems in low oxidation states (i.e. zero or below) has been attempted, but with limited success ${ }^{15-20}$. Thermodynamics typically drive the aggregation of molecular $\mathrm{Au}(0)$ systems to clusters of colloidal gold ${ }^{15-18}$. Recently however, electron-rich gold complexes have been reported by Bertrand and co-workers, by making use of strongly $\pi$-accepting cyclic(alkyl)(amino)carbenes (CAAC) ligands (I and II, Figure 1) ${ }^{19}$. In addition, a four-coordinate molecular 'boroauride' was reported by Harman and co-workers last year in which the gold centre is stabilized by a diboraanthracene-based scaffold (III, Figure 1$)^{20}$. Notwithstanding these examples, and even though $\mathrm{Au}^{-}$ions have previously been observed to react as nucleophiles in the gas phase ${ }^{21}$, examples of nucleophilic reactivity by molecular gold systems in solution have not been reported. 

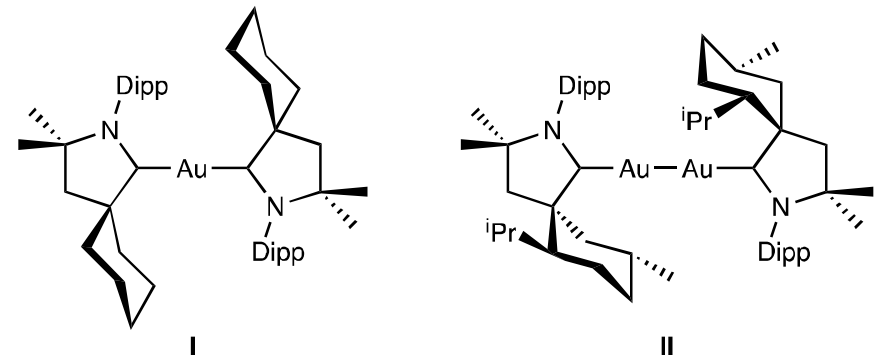

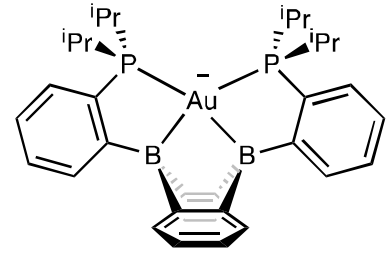

III

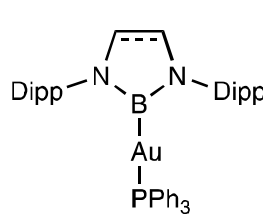

IV

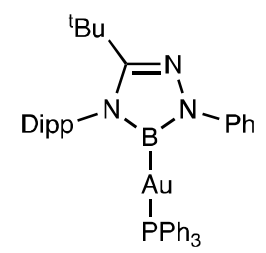

V

Figure 1. Selected examples of electron rich gold complexes. Gold complexes featuring cyclic amino alkyl carbene (cAAC) ligands (I and II); a four-coordinate complex described as a 'boroauride' (III) and two-coordinate gold boryl phosphine complexes (IV and V).

Over the last decade, boryl anions have been utilized as highly $\sigma$-donating ligands in conjunction with numerous metals from throughout the Periodic Table ${ }^{22,23}$. Included in these studies are twocoordinate gold complexes of the type $\mathrm{Ph}_{3} \mathrm{PAu}$ (boryl) (boryl $=\mathrm{B}\{\mathrm{N}(\mathrm{Dipp}) \mathrm{CH})_{2}$ or $\mathrm{B}\left\{\mathrm{N}(\mathrm{Dipp}) \mathrm{C}\left({ }^{\mathrm{t} B u}\right) \mathrm{NNPh}\right\}$; Dipp = 2,6-diisopropylphenyl) reported by Yamashita, Nozaki and coworkers (IV, Figure 1$)^{24}$ and by Kinjo et al. (V, Figure 1$)^{25}$. Even though boryl ligands are known to be highly electron donating, and the difference in electronegativity between gold and boron (2.54 and 2.04, respectively $)^{26}$ implies a $\mathrm{Au}(\delta-)-\mathrm{B}(\delta+)$ polarity to these bonds, no gold-centered nucleophilic reactivity has been reported for these systems. In the current study we make use of an extremely strongly donating aluminyl ligand to synthesise a two-coordinate molecular species featuring a highly polarized $\mathrm{Au}(\delta-)-\mathrm{Al}(\delta+)$ bond, that shows for the first time that gold can act as a nucleophile in the solution phase. 


\section{Results and Discussion}

\section{Syntheses}

In recent work, we reported the preparation and characterization of the potassium aluminyl $[\mathrm{K}\{\mathrm{Al}(\mathbf{N O N})\}]_{2} \quad(\mathbf{1}, \quad$ where $\quad \mathbf{N O N}=4,5$-bis(2,6-diisopropylanilido)-2,7-di-tert-butyl-9,9dimethylxanthene) and demonstrated that this complex reacts as an aluminium-centred nucleophile $^{27}$. Reactions with (NON)AlI and $\left({ }^{\mathrm{Mes} N a c n a c}\right) \operatorname{MgI}\left(\mathrm{OEt}_{2}\right)$ (where ${ }^{\mathrm{Mes}} \mathrm{Nacnac}=$ $(\mathrm{NMesCMe})_{2} \mathrm{CH}$, and $\left.\mathrm{Mes}=2,4,6-\mathrm{Me}_{3} \mathrm{C}_{6} \mathrm{H}_{2}\right)$ lead to the formation of unsupported metal-metal bonds in $[\mathrm{Al}(\mathbf{N O N})]_{2}$ and (NON)AlMg$\left({ }^{\mathrm{Mes}} \mathrm{Nacnac}\right)$, respectively. We were interested in expanding this chemistry to the $d$-block metals, in particular gold, as systems of the type $\mathrm{R}_{3} \mathrm{PAuX}$ are well known catalysts/precatalysts in numerous organic reactions involving alkynes in which gold acts exclusively as an electrophile ${ }^{28}$. We hypothesized that by incorporating the extremely electron donating aluminyl fragment into such a system, the mode of reactivity could be reversed, i.e. making gold nucleophilic. Accordingly, 1 was found to react with two phosphine-ligated gold(I) iodide complexes, $\mathrm{Ph}_{3} \mathrm{PAuI}$ and ${ }^{\mathrm{t}} \mathrm{Bu}{ }_{3} \mathrm{PAuI}$, to give (NON)Al$\left(\mathrm{AuPPh}_{3}\right)_{2} \mathrm{I}(\mathbf{2})$ and $(\mathbf{N O N}) \mathrm{AlAuP}^{\mathrm{t}} \mathrm{Bu}_{3}$ (3), respectively (Figure 2). Compound 2 was synthesized by the addition of $\mathrm{Ph}_{3} \mathrm{PAuI}$ to a solution of $\mathbf{1}$ in toluene at room temperature in a 2:1 ratio of Au:Al. It is proposed that the reaction proceeds via the two-coordinate gold intermediate $(\mathrm{NON}) \mathrm{AlAuPPh}_{3}$, which rapidly reacts with a further equivalent of $\mathrm{Ph}_{3} \mathrm{PAuI}$ to give the isolated complex 2. In an attempt to isolate this intermediate, one equivalent of $\mathrm{Ph}_{3} \mathrm{PAuI}$ was added to a toluene solution of 1 at $-78^{\circ} \mathrm{C}$, and the reaction mixture slowly warmed to room temperature. However this procedure simply led to a 1:1 mixture of 2 and unreacted aluminyl 1. By contrast, the addition of one equivalent of the bulkier system ${ }^{t} \mathrm{Bu}_{3} \mathrm{PAuI}$ to a toluene solution of $\mathbf{1}$ resulted in a clean reaction to give the two-coordinate gold complex $\mathbf{3}$ in high crystalline yield (Figure 2). Presumably, the bulkier tritertbutylphosphine ligand prevents 3 
from reacting with a further equivalent of ${ }^{\mathrm{t}} \mathrm{Bu} 3 \mathrm{PAuI}$ at room temperature, even when excess ${ }^{\mathrm{t}} \mathrm{Bu} \mathrm{H}_{3} \mathrm{PAuI}$ is added.

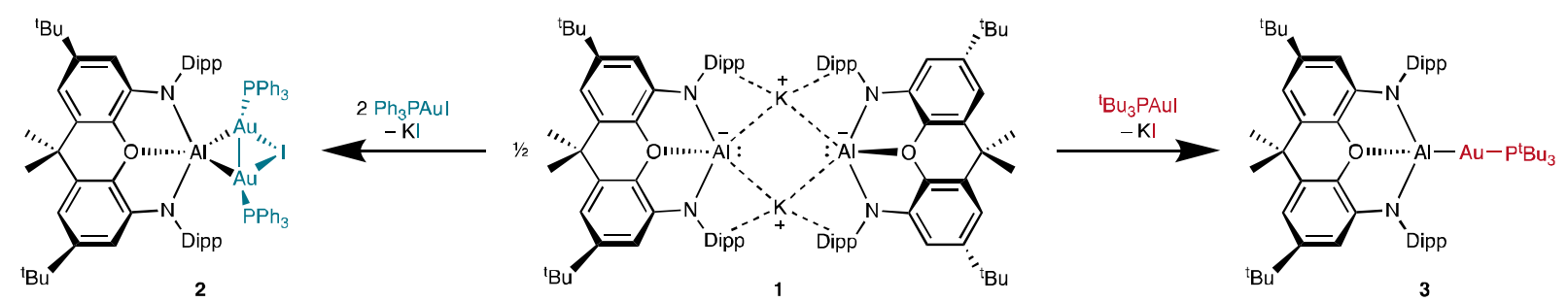

Figure 2. Synthesis of the tri- and bimetallic gold/aluminium complexes 2 and 3. Reaction of the potassium aluminyl species 1 with two equivalents of $\mathrm{Ph}_{3} \mathrm{PAuI}$ yields the aluminium digold iodide species $\mathbf{2}$, whereas the reaction of $\mathbf{1}$ with one equivalent of the bulkier system ${ }^{\mathrm{t}} \mathrm{Bu} 3 \mathrm{PAuI}$ gives hetero-bimetallic species $\mathbf{3}$.

Taking the relative electronegativities of gold and aluminium into account, both of the Al-Au bond forming reactions could be regarded as bringing about a formal two-electron oxidation of the aluminium centre from +1 to +3 . In the reaction to give 2 , this would be accompanied by oneelectron reduction of each of the two gold centres. The resulting $\mathrm{Al}(\mathrm{III}) \mathrm{Au}(0)_{2}$ formalism is consistent with structural metrics - notably the Au-Au distance (vide infra). In the formation of $\mathbf{3}$ however, a similar redox formalism would necessitate two-electron reduction of the single gold centre from +1 to -1 . With a view to providing a more rigorous interpretation of the $\mathrm{Al}-\mathrm{Au}$ bonding in $\mathbf{3}$, and the transfer of charge accompanying bond formation, NOCV calculations were carried out. ${ }^{29-31}$ Constructing 3 by bringing together $[\mathrm{Al}(\mathrm{NON})]^{-}$and $\left[\mathrm{AuP}^{t} \mathrm{Bu}_{3}\right]^{+}$fragments shows that the most important NOCV describes a polarized $\sigma$-bond corresponding to donation of the aluminium lone pair to the gold centre. This interaction contributes $70 \%$ of the total orbital interaction energy. Moreover, quantum theory of atoms in molecules (QTAIM) charge analysis indicates that $\mathrm{Al}-\mathrm{Au}$ 
bond formation in 3 induces a transfer of 1.56 electrons from the [(NON)Al] $]^{-}$fragment to the $\left[\mathrm{AuP}^{t} \mathrm{Bu}_{3}\right]^{+}$group. Notably, however, the lowest energy pathway for breakage of the Au-Al bond is homolytic, consistent with a description of $\mathbf{3}$ in valence terms as featuring a $\mathrm{X}$-type aluminyl ligand and a $\mathrm{Au}(\mathrm{I}) \mathrm{Al}(\mathrm{III})$ valence formalism.

\section{Structural characterization of the Al-Au bonded complexes 2 and 3}

Both $\mathbf{2}$ and $\mathbf{3}$ could be isolated as analytically pure crystalline materials which are stable at room temperature in solution and in the solid state over the course of several weeks. The molecular structures of both complexes are monomeric in the solid state (Figure 3). That of 2 reveals an essentially planar $\mathrm{AlAu}_{2} \mathrm{I}$ core, with one triphenylphosphine ligand coordinated to each of the two gold centres. The aluminium and iodine centres bridge the $\mathrm{Au}_{2}$ unit in a slightly unsymmetrical fashion (Al-Au bond lengths: 2.6045(18) and 2.5093(19) $\AA$; Au-I bond lengths: 3.1447(7) and 2.8431(7) $\AA$ ). This asymmetry is likely due to steric buttressing between the bulky NON and triphenylphosphine ligands. The Al-O and Al-N bond lengths $(\mathrm{Al}-\mathrm{O}=1.992(4) \AA, A l-\mathrm{N}=$ 1.916(5) and 1.916(5) $\AA$ ) are significantly shorter than those in the aluminyl starting material 1 $(\mathrm{Al}-\mathrm{O}=2.279(2) \AA, \mathrm{Al}-\mathrm{N}=1.956(2) \text { and } 1.963(2) \AA)^{27}$, and are more in line with [(NON)Al] complexes featuring trivalent aluminium (e.g. $(\mathrm{NON}) \mathrm{AlH} ; \mathrm{Al}-\mathrm{O}=1.944(2) \AA, \mathrm{Al}-\mathrm{N}=1.873(1)$ and $1.872(1) \AA)^{27}$. The Au-Au distance $(2.5897(6) \AA)$ is towards the shorter end of the range of known complexes featuring $\mathrm{Au}-\mathrm{Au}$ bonds, and is comparable to that of Bertrand's digold system $[\mathrm{Au}(\mathrm{CAAC})]_{2}(\mathbf{I I}, \mathrm{Au}-\mathrm{Au}=2.5520(6) \AA)^{19,32}$, consistent with a description of $\mathbf{2}$ featuring a formal $\mathrm{Au}-\mathrm{Au}$ single covalent bond. 

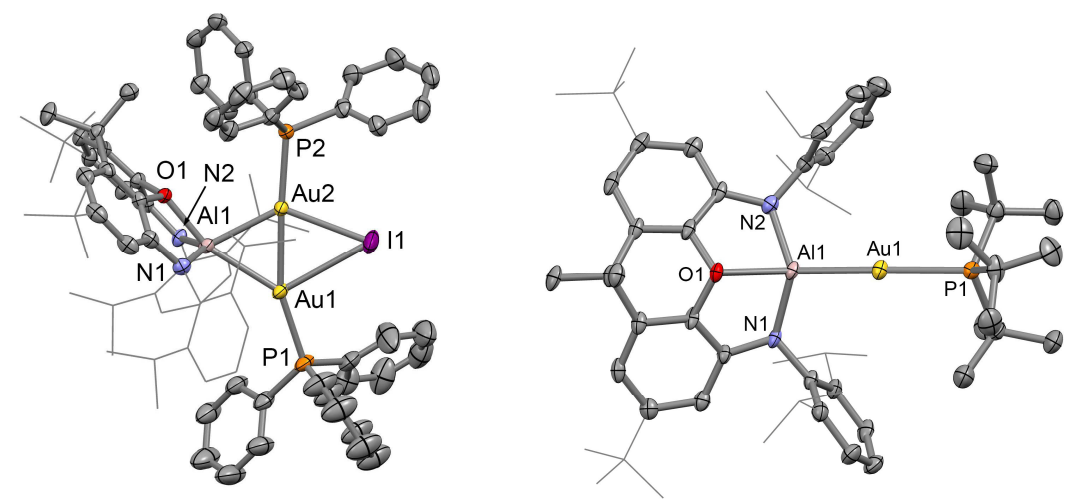

Figure 3. Molecular structures of 2 and 3 as determined by X-ray crystallography. Thermal ellipsoid plots of $\mathbf{2}$ (left) and $\mathbf{3}$ (right) at 50\% probability level; hydrogen atoms are omitted and parts of the NON ligand are drawn in a wireframe format for clarity. Selected bond distances and angles: 2, $\mathrm{Au}(1)-\mathrm{Au}(2)$ 2.5897(6) $\AA, \mathrm{Al}(1)-\mathrm{Au}(1)$ 2.6045(18) $\AA, \mathrm{Al}(1)-\mathrm{Au}(2) 2.5897(6) \AA$,

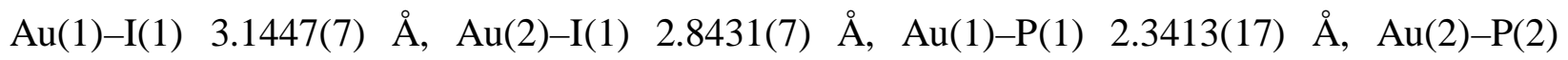
2.3328(16) $\mathrm{A}, \mathrm{Al}(1)-\mathrm{N}(1) 1.916(5) \AA, \mathrm{Al}(1)-\mathrm{N}(2) 1.916(5) \AA, \mathrm{Al}(1)-\mathrm{O}(1)$ 1.992(4) $\mathrm{A}, \mathrm{Al}(1)-$ $\mathrm{Au}(1)-\mathrm{P}(1) 140.50(6)^{\circ}, \mathrm{Al}(1)-\mathrm{Au}(2)-\mathrm{P}(2) 121.51(6)^{\circ} ; 3, \mathrm{Al}(1)-\mathrm{Au}(1) 2.402(3) \AA$ 2.395(3) $\mathrm{A}, \mathrm{Al}(1)-\mathrm{N}(1) 1.900(10) \AA, \mathrm{Al}(1)-\mathrm{N}(2)$ 1.904(10) $\AA, \mathrm{Al}(1)-\mathrm{O}(1) 2.046(8) \AA, \mathrm{Al}(1)-$ $\mathrm{Au}(1)-\mathrm{P}(1) 167.47(10)^{\circ}$.

The molecular structure of $\mathbf{3}$ reveals a two-coordinate gold centre bound to one $\mathrm{P}^{\mathrm{t}} \mathrm{Bu}_{3}$ ligand and one (NON)Al unit, with the Al-Au-P unit defining a near linear geometry $\left(167.47(10)^{\circ}\right)$. The AlAu bond length is 2.402(3) $\AA$, which is by far the shortest Al-Au bond to be reported to date (previous shortest: $2.596(5) \AA)^{33}$ and well within the sum of the covalent radii of the two elements $(2.57 \AA)^{34}$. Moreover, complex 3 represents the first example of a crystallographically characterized complex bearing an unsupported $\mathrm{Al}-\mathrm{Au}$ bond. ${ }^{35,36}$ As with $\mathbf{2}$, the $\mathrm{Al}-\mathrm{N}$ and $\mathrm{Al}-\mathrm{O}$ bond lengths $(\mathrm{Al}-\mathrm{N}=1.900(10)$ and $1.904(10) \AA, A l-O=2.046(8) \AA)$ are significantly shorter 
than those found in the aluminyl starting material 1, being more in line with those found in trivalent systems such as (NON)AlH ${ }^{27}$.

\section{Charge analysis of 2 and 3}

In order to study the charge distribution in the two $\mathrm{Al}-\mathrm{Au}$ bonded complexes, the effective atomic charges of all atoms in $\mathbf{2}$ and $\mathbf{3}$ were calculated using QTAIM (see Supplementary Information

section 5 for further details $)^{37,38}$. In 2 , the total charge on the $\mathrm{Al}(\mathbf{N O N})$ fragment is +0.50 whereas in $\mathbf{3}$ the corresponding charge is +0.56 . In $\mathbf{2}$, the balancing negative charge is mostly localized at iodine, and the $\left(\mathrm{AuPPh}_{3}\right)_{2}$ fragment is approximately neutral, suggesting a covalent $\mathrm{Au}-\mathrm{Au}$ bond. The effective charges on the aluminium centres in $\mathbf{2}$ and $\mathbf{3}$ are +2.27 and +2.21 respectively (Figure $4)$, i.e. considerably higher than that calculated for the $[\mathrm{Al}(\mathrm{NON})]^{-}$fragment $(+0.95)$. The effective charges on the gold atoms in $\mathbf{2}$ are -0.42 and -0.40 , while that in $\mathbf{3}$ is -0.82 (Figure 4 ), consistent with a description of $\mathbf{3}$ as featuring a strongly polarized bond, $\mathrm{Au}(\delta-)-\mathrm{Al}(\delta+)$. The calculation of atomic charges is known to be method dependent, and with this in mind, the corresponding atomic charges in the boryl gold system $\left\{(\mathrm{HCDippN})_{2} \mathrm{~B}\right\} \mathrm{AuPPh}_{3}{ }^{24}$ (Figure 1, IV) were also calculated using the QTAIM approach in order to provide like-for-like comparison. This system was found to possess a significantly less polar B-Au bond ( $c f$. the Al-Au bond in $\mathbf{3}$ ), with a smaller positive charge located on the boron centre $(+1.39)$ and a much smaller negative charge on the gold ($0.20)$. 

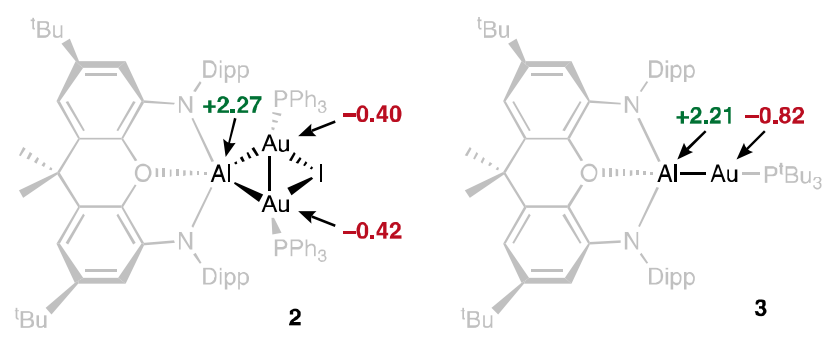

Figure 4. Calculated effective atomic charges for the $\mathrm{Al}$ and Au centres in 2 and 3. The effective atomic charges of all atoms in $\mathbf{2}$ and $\mathbf{3}$ were calculated using the QTAIM method. Both complexes were found to contain similar charges on the Al centres, +2.27 for $\mathbf{2}$ and +2.21 for $\mathbf{3}$, but complex $\mathbf{3}$ was found to have a significantly higher negative charge located on the gold centre $(-0.82)$ than in $2(-0.40$ and -0.42$)$.

\section{Reactivity of 3}

Given that the calculated charge on gold in compound $\mathbf{3}$ is close to -1 , its possible reactivity as a gold-centred nucleophile was investigated. Accordingly, $\mathbf{3}$ was reacted with a range of unsaturated carbon-centred electrophiles. Reactions with simple aldehydes and ketones were investigated, targeting complexes of the type $(\mathrm{NON}) \mathrm{AlO}(\mathrm{R})_{2} \mathrm{CAuP}^{\mathrm{t}} \mathrm{Bu}$. However, these reactions lead to complex mixtures, presumably due to the fact that the initially-formed products contain a highly Lewis acidic aluminium centre, which reacts further with the carbonyl substrates. With this in mind, heteroallenes, such as carbodiimides and $\mathrm{CO}_{2}$ were targeted, on the basis that the product might chelate the aluminium centre and quench its Lewis acidity. Accordingly, one equivalent of diisopropylcarbodiimide was added to a toluene solution of $\mathbf{3}$ at room temperature, leading to clean formation of the insertion product (NON)Al $\left\{\left(N^{i} P r\right)_{2} \mathrm{C}\right\} \mathrm{AuP}^{t} \mathrm{Bu}_{3}(4)$. In a similar fashion, exposure to one atmosphere of $\mathrm{CO}_{2}$ at room temperature leads to the formation of $(\mathrm{NON}) \mathrm{Al}\left(\mathrm{O}_{2} \mathrm{C}\right) \mathrm{AuP}^{t} \mathrm{Bu}_{3}$ (5) (Figure 5). The identities of both $\mathbf{4}$ and $\mathbf{5}$ were verified crystallographically (Figure 5 and 
Supplementary Figure 7): they are essentially isostructural, with a single molecule of diisopropylcarbodiimide (4) or $\mathrm{CO}_{2}(5)$ reductively inserted into the $\mathrm{Al}-\mathrm{Au}$ bond. The resulting metalla-amidinate/-carboxylate fragment chelates the aluminium centre through the two heteroatoms ( $\mathrm{N}$ in $\mathbf{4}$ and $\mathrm{O}$ in $\mathbf{5}$ ), with the gold centre being bound to carbon in each case, consistent with nucleophilic attack by gold at the electrophilic central carbon atom. The $\mathrm{N}-\mathrm{C}$ bond lengths

in $4(1.336(13)$ and $1.339(13) \AA)$ and the O-C bond lengths in 5 (1.289(8) and 1.285(8) $\AA$ ) associated with the $\mathrm{Al}\left(\mathrm{E}_{2} \mathrm{C}\right) \mathrm{Au}$ unit fall between the typical ranges for $\mathrm{N}-\mathrm{C}$ and $\mathrm{C}-\mathrm{O}$ single and double bonds, supporting the idea of a formal two-electron reduction of the ${ }^{i} \operatorname{PrNCN} \operatorname{Pr} / \mathrm{CO}_{2}$ substrate. To the best of our knowledge, 5 represents the first crystallographically verified example of simple $\mathrm{CO}_{2}$ insertion into any metal-metal bond ${ }^{39,40}$. In addition, it represents the first example of gold(I) metalla-carboxylate complex ${ }^{41}$.
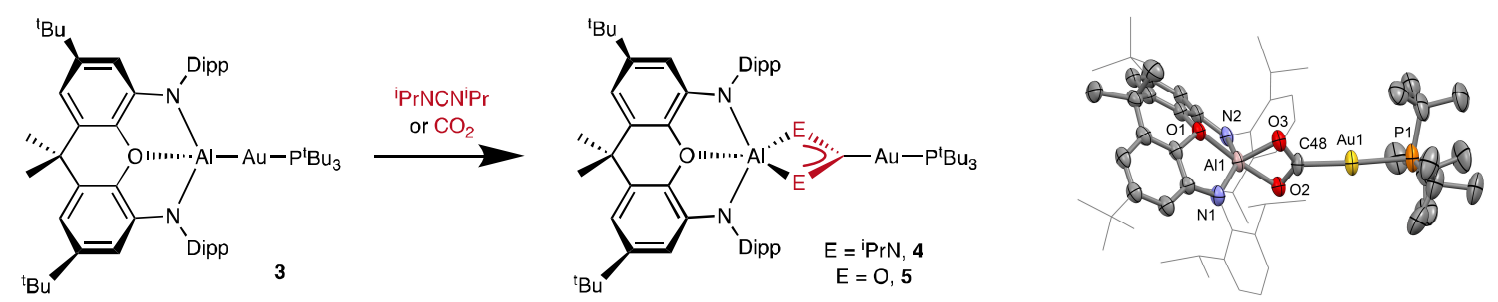

Figure 5. Reductive insertion of diisopropylcarbodiimide and $\mathrm{CO}_{2}$ into the Al-Au bond of 3 and the molecular structure of 5 as determined by X-ray crystallography. The reaction of 3 with one equivalent of diisopropylcarbodiimide or one atmosphere of $\mathrm{CO}_{2}$ in toluene leads to the reductive insertion of the heteroallene to give $\mathbf{4}$ and $\mathbf{5}$ respectively. In both reactions, the gold centre is acting as a nucleophile, attacking the central carbon atom of both heteroallenes. Thermal ellipsoid plots of $\mathbf{5}$ at $50 \%$ probability level; hydrogen atoms are omitted and parts of the NON ligand are drawn in a wireframe format for clarity. 
Spectroscopically, the ${ }^{13} \mathrm{C}\left\{{ }^{1} \mathrm{H}\right\}$ NMR spectra of $\mathbf{4}$ and $\mathbf{5}$ feature doublets corresponding to the goldbound carbon atoms $\left({ }^{2} J_{\mathrm{PC}}=101\right.$ and $134 \mathrm{~Hz}$, respectively) at remarkably downfield chemical shifts (4: $219.9 \mathrm{ppm} ; \mathbf{5}: 242.3 \mathrm{ppm})$, suggestive of carbene-like character in the [(NON)AlE $\left.{ }_{2} \mathrm{C}\right]$ moiety. These shifts are even more downfield than those reported for tritertbutylphosphine/ $\mathrm{N}$-heterocyclic carbene complexes of gold such as $\left[(\operatorname{IPr}) \mathrm{AuP}^{t} \mathrm{Bu}_{3}\right]\left[\mathrm{BF}_{4}\right]\left(\delta_{\mathrm{C}}=191.9 \mathrm{ppm} ; \quad \operatorname{IPr}=\right.$ $\left.\mathrm{C}\{\mathrm{N}(\text { Dipp }) \mathrm{CH}\}_{2}\right)^{42}$, suggesting that significant contributing resonance forms for complexes 4 and 5 are as anionic carbene complexes of gold (Figure 6).

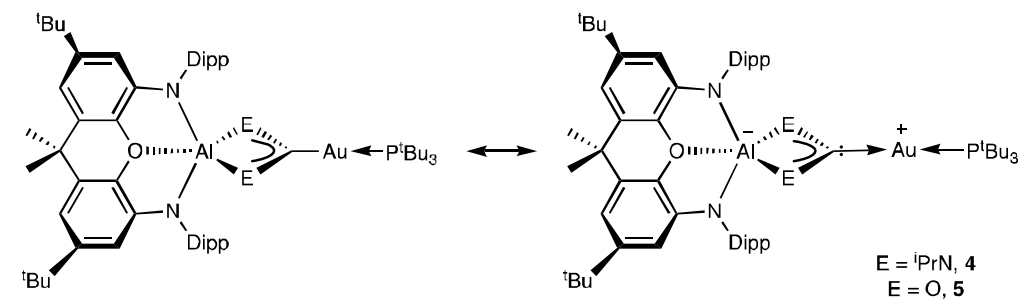

Figure 6. Resonance structures of 4 and $5 .{ }^{13} \mathrm{C}\left\{{ }^{1} \mathrm{H}\right\}$ NMR spectra of $\mathbf{4}$ and $\mathbf{5}$ show remarkably downfield chemical shifts for the $\mathrm{AlE}_{2} \mathrm{CAu}$ carbon atoms (219.9 ppm for 4 and $242.3 \mathrm{ppm}$ and 5), suggestive of carbene-like character.

In summary, the potassium aluminyl complex 1 reacts with two phosphine-ligated gold iodide complexes, $\mathrm{Ph}_{3} \mathrm{PAuI}$ and ${ }^{\mathrm{t}} \mathrm{Bu} 3 \mathrm{PAuI}$, to give the tri- and bimetallic systems (NON)Al( $\left(\mathrm{AuPPh}_{3}\right)_{2} \mathrm{I}$ (2) and (NON)AlAuPtBu $3(3)$, respectively. Crystallographic and computational analyses of complex $\mathbf{3}$ is in line with a description as a heterobimetallic complex featuring a strongly polarized covalent bond, $\mathrm{Au}(\delta-)-\mathrm{Al}(\delta+)$, and is supported by a QTAIM calculated charge of -0.82 at $\mathrm{Au}$. Consistently, $\mathbf{3}$ reacts as a gold centred nucleophile; its reactions with diisopropylcarbodiimide and $\mathrm{CO}_{2}$ give the reductive insertion products $\mathbf{4}$ and $\mathbf{5}$ featuring $\mathrm{Au}-\mathrm{C}$ bonds. To our knowledge this is the first time that nucleophilic reactivity by a molecular gold compound has been observed 
in solution.

\section{Methods}

Manipulations were carried out under a dry, oxygen-free argon or dinitrogen atmosphere, with reagents dissolved or suspended in aprotic solvents, and combined or isolated using cannula and glove box techniques. (NON)Al( $\left(\mathrm{AuPPh}_{3}\right)_{2} \mathrm{I}(\mathbf{2})$ and $(\mathbf{N O N}) \mathrm{AlAuP}^{t} \mathrm{Bu}_{3}(\mathbf{3})$ were synthesized by the addition of the appropriate gold phosphine iodide ( $\mathrm{Ph}_{3} \mathrm{PAuI}$ for $\mathbf{2}$ and ${ }^{\mathrm{t}} \mathrm{Bu} 3 \mathrm{PAuI}$ for $\left.\mathbf{3}\right)$ to a toluene solution of $[\mathrm{K}\{\mathrm{Al}(\mathbf{N O N})\}]_{2}(\mathbf{1})$. It was found that $\mathbf{2}$ could also be synthesised by the addition of $\mathrm{Ph}_{3} \mathrm{PAuI}$ to a toluene solution of $\mathbf{3}$. The reactions of $\mathbf{3}$ with the heteroallenes diisopropylcarbodiimide and $\mathrm{CO}_{2}$ lead to reductive insertion of the substrates into the $\mathrm{Al}-\mathrm{Au}$ bond, to give $(\mathbf{N O N}) \mathrm{Al}\left\{\left(\mathrm{N}^{\mathrm{i} P r}\right)_{2} \mathrm{C}\right\} \mathrm{AuP}^{t} \mathrm{Bu}_{3}(\mathbf{4})$ and $(\mathbf{N O N}) \mathrm{Al}\left(\mathrm{O}_{2} \mathrm{C}\right) \mathrm{AuP}^{t} \mathrm{Bu}_{3}(\mathbf{5})$ respectively. All new compounds $\mathbf{2}-\mathbf{5}$ were characterized by elemental analysis, multinuclear NMR spectroscopy and single-crystal X-ray diffraction. Density Functional Theory (DFT), as implemented in the Amsterdam Density Functional code, was employed to calculate molecular geometries, bonding energies, natural orbitals of the chemical valence (NOCV) and quantum theory of atoms in molecules (QTAIM) charges for complexes 2 and 3. Scalar relativistic effects were treated using the zeroth order regular approximation (ZORA) in all DFT calculations. A comprehensive computational methods section is included in the Supporting Information, section 5. 


\section{Data availability statement}

Data are available via the Oxford University Research Archive (https://ora.ox.ac.uk). X-ray crystallographic data for compounds $\mathbf{2}, \mathbf{3}, \mathbf{4}$ and $\mathbf{5}$ are available from the Cambridge Crystallographic Data Centre (CCDC 1854971-1854974). 


\section{References}

1. Cotton, F. A., Wilkinson, G., Murillo, C. A. \& Bochmann, M. Advanced Inorganic Chemistry (6th ed.). (Wiley-Interscience, 1999).

2. Tolman, W. Activation of small molecules. (Wiley-VCH, 2006).

3. Cornils, B. \& Herrmann, W. Applied homogeneous catalysis with organometallic compounds. (Wiley-VCH, 1996).

4. Bacci, M., Fischer, J., Gubelmann, M., Koren, B., Mathey, F., Melnik, M., Nelson, J., Sivy, P., Valach, F. \& Williams, A. Transition Metal Complexes - Structures and Spectra. (Springer, 2014).

5. Hieber, W. \& Leutert, F. Äthylendiamin-substituierte Eisencarboyle und eine neue Bildungsweise von Eisencarbonylwasserstoff (XI. Mitteil. über Metallcarbonyle). Chem. Ges. 64, 2832-2839 (1931).

6. Elschenbroich, C. \& Gerson, F. Metal-.pi.-complexes of benzene derivatives. VI. Bis(.eta.benzene)vanadium(-I) anion. J. Am. Chem. Soc. 97, 3556-3557 (1975).

7. Ellis, J. E. Adventures with Substances Containing Metals in Negative Oxidation States. Inorg. Chem. 45, 3167-3186 (2006).

8. Jansen, M. The chemistry of gold as an anion. Chem. Soc. Rev. 37, 1826-1835 (2008).

9. Jansen, M. Effects of relativistic motion of electrons on the chemistry of gold and platinum. Solid State Sci. 7, 1464-1474 (2005).

10. Andersen, T., Haugen, H. K. \& Hotop, H. Binding Energies in Atomic Negative Ions: III. J. Phys. Chem. Ref. Data 28, 1511-1533 (1999). 
11. Sommer, A. H. Alloys of Gold with Alkali Metals. Nature 152, 215-215 (1943).

12. Spicer, W. E., Sommer, A. H. \& White, J. G. Studies of the Semiconducting Properties of the Compound CsAu. Phys. Rev. 115, 57-62 (1959).

13. Peer, W. J. \& Lagowski, J. J. Metal-ammonia solutions. 11. Gold(1-), a solvated transition metal anion. J. Am. Chem. Soc. 100, 6260-6261 (1978).

14. Dietzel, P. D. C. \& Jansen, M. Synthesis and crystal structure determination of tetramethylammonium auride. Chem. Commun. 621, 2208-2209 (2001).

15. Tsui, E. Y., Müller, P. \& Sadighi, J. P. Reactions of a Stable Monomeric Gold(I) Hydride Complex. Angew. Chem., Int. Ed. 47, 8937-8940 (2008).

16. Schmidbaur, H. \& Dash, K. C. Compounds of Gold in Unusual Oxidation States. Adv. Inorg. Chem. 25, 239-266 (1982).

17. Mézailles, N., Avarvari, N., Maigrot, N., Ricard, L., Mathey, F., Floch, P. L., Cataldo, L., Berclaz, T. \& Geoffroy, M. Gold(I) and Gold(0) Complexes of Phosphinine-Based Macrocycles. Angew. Chem., Int. Ed. 38, 3194-3197 (1999).

18. McIntosh, D. \& Ozin, G. A. Synthesis of binary gold carbonyls, $\mathrm{Au}(\mathrm{CO}) \mathrm{n}(\mathrm{n}=1$ or 2$)$. Spectroscopic evidence for isocarbonyl(carbonyl)gold, a linkage isomer of bis(carbonyl)gold. Inorg. Chem. 16, 51-59 (1977).

19. Weinberger, D. S., Melaimi, M., Moore, C. E., Rheingold, A. L., Frenking, G., Jerabek, P. \& Bertrand, G. Isolation of Neutral Mono- and Dinuclear Gold Complexes of Cyclic (Alkyl)(amino)carbenes. Angew. Chem., Int. Ed. 52, 8964-8967 (2013). 
20. Taylor, J. W., McSkimming, A., Moret, M.-E. \& Harman, W. H. A Molecular Boroauride: A Donor-Acceptor Complex of Anionic Gold. Angew. Chem., Int. Ed. 56, 10413-10417 (2017).

21. Boese, A. D., Schneider, H., Glöß, A. N. \& Weber, J. M. The infrared spectrum of Au ${ }^{-}$ .CO2. J. Chem. Phys. 122, 154301-154307 (2005).

22. Segawa, Y., Yamashita, M. \& Nozaki, K. Boryllithium: Isolation, Characterization, and Reactivity as a Boryl Anion. Science 314, 113-115 (2006).

23. Weber, L. 1,3,2-Diazaborolyl Anions - From Laboratory Curiosities to Versatile Reagents in Synthesis. Eur. J. Inorg. Chem. 3461-3488 (2017).

24. Segawa, Y., Yamashita, M., \& Nozaki, K. Boryl Anion Attacks Transition-Metal Chlorides To Form Boryl Complexes: Syntheses, Spectroscopic, and Structural Studies on Group 11 Borylmetal Complexes. Angew. Chem., Int. Ed. 46, 6710-6713 (2007).

25. Lu, W., Hu, H., Li, Y., Ganguly, R. \& Kinjo, R. Isolation of 1,2,4,3-Triazaborol-3-yl-metal (Li, Mg, Al, Au, Zn, Sb, Bi) Derivatives and Reactivity toward CO and Isonitriles. J. Am. Chem. Soc. 138, 6650-6661 (2016).

26. Emsley, J. The Elements, 2nd ed. (Oxford, 1995).

27. Hicks, J., Vasko, P., Goicoechea, J. M. \& Aldridge, S. Synthesis, structure and reaction chemistry of a nucleophilic aluminyl anion. Nature 557, 92-95 (2018).

28. Wegner, H. A. \& Auzias M. Gold for C-C Coupling Reactions: A Swiss-Army-Knife Catalyst? Angew. Chem., Int. Ed. 50, 8236-8247 (2011). 
29. Mitoraj M., \& Michalak, A. Natural orbitals for chemical valence as descriptors of chemical bonding in transition metal complexes. J. Mol. Modeling 13, 347-355 (2007).

30. Michalak, A., Mitoraj, M. \& Ziegler, T. Bond Orbitals from Chemical Valence Theory. $J$. Phys. Chem. A 112, 1933-1939 (2008).

31. Radoń, M. On the properties of natural orbitals for chemical valence. Theor. Chem. Acc. 120, 337-339 (2008).

32. Gabbaï, F. P., Schier, A., Riede, J. \& Schmidbaur, H. Different pathways of the reaction of $\mathrm{InCl}$ with $\mathrm{Ph}_{3} \mathrm{PAuCl}$ : isolation of the first mixed-valent mixed-metal gold/indium cluster Inorg. Chem. 34, 3855-3856 (1995).

33. Puls, A., Jerabek, P., Kurashige, W., Forster, M., Molon, M., Bollermann, T., Winter, M., Gemel, C., Negishi, Y., Frenking, G. \& Fischer, R. A. A novel concept for the synthesis of multiply doped gold clusters $\left[\left(\mathrm{M} @ \mathrm{Au}_{n} \mathrm{M}_{m}^{\prime}\right) \mathrm{L}_{k}\right]^{q+}$. Angew. Chem., Int. Ed. 53, 4327-4331 (2014).

34. Cordero, B., Gomez, V., Platero-Prats, A. E., Reves, M., Echeverria, J., Cremades, E., Barragan, F. \& Alvarez, S. Covalent radii revisited. Dalton Trans. 2832-2838 (2008).

35. Kempter, A., Gemel, C. \& Fischer, R. A. Insertion of $\mathrm{Ga}(\mathrm{DDP})$ into the $\mathrm{Au}-\mathrm{Cl}$ bond of $\left(\mathrm{PPh}_{3}\right) \mathrm{AuCl}$ : a first structurally characterized $\mathrm{Au}-\mathrm{Ga}$ bond Inorg. Chem. 44, 163-165 (2005).

36. Green, S. P., Jones, C., Mills, D. P. \& Stasch, A. Group 9 and 11 metal(I) gallyl complexes stabilized by N-heterocyclic carbene coordination: first structural characterization of GaM (M - Cu or Ag) bonds. Organometallics 26, 3424-3430 (2007). 
37. Bader, R. F. W. A quantum theory of molecular structure and its applications. Chem. Rev. 91, 893-928 (1991).

38. Bader, R. F. W. Atoms in Molecules. A Quantum Theory. (Oxford University Press, 1994).

39. Pinkes, J. R., Steffey, B. D., Vites J. C. \& Cutler, A. R. Carbon dioxide insertion into the iron-zirconium and ruthenium-zirconium bonds of the heterobimetallic complexes $\mathrm{Cp}(\mathrm{CO})_{2} \mathrm{M}-\mathrm{Zr}(\mathrm{Cl}) \mathrm{Cp}_{2}$ : direct production of the $\mu-\eta^{1}(\mathrm{C}): \eta^{2}\left(\mathrm{O}, \mathrm{O}^{\prime}\right)-\mathrm{CO}_{2}$ compounds $\mathrm{Cp}(\mathrm{CO})_{2} \mathrm{M}-\mathrm{CO}_{2}-\mathrm{Zr}(\mathrm{Cl}) \mathrm{Cp}_{2}$. Organometallics 13, 21-23 (1994).

40. Li, J., Hermann, M., Frenking, G. \& Jones, C. The Facile Reduction of Carbon Dioxide to Carbon Monoxide with an Amido-Digermyne. Angew. Chem., Int. Ed. 51, 8611-8614 (2012).

41. Komiya, S., Sone, T., Ozaki, S., Ishikawa, M. \& Kasuga, N. Synthesis, structure and properties of dimethyl(alkoxycarbonyl)gold(III) complexes having a triphenylphosphine ligand. J. Organomet. Chem. 428, 303-313 (1992).

42. Gaillard, S., Nun, P., Slawin, A. M. Z. \& Nolan, S. P. Expeditious Synthesis of $[\mathrm{Au}(\mathrm{NHC})(\mathrm{L})]+(\mathrm{NHC}=\mathrm{N}-$ Heterocyclic Carbene; $\mathrm{L}=$ Phosphine or NHC $)$ Complexes. Organometallics 29, 5402-5408 (2010). 
Supplementary Information is linked to the online version of the paper at www.nature.com/nature.

Acknowledgments This work was supported by the SCG-Oxford Centre of Excellence. P.V. thanks the Magnus Ehrnrooth, Finnish Cultural and Emil Aaltonen Foundations for postdoctoral funding. Computational resources were provided by CSC - IT Center for Science, Finland, the Finnish Grid and Cloud Infrastructure (persistent identifier nrn:nbn:fi:research-infras2016072533), and the University of Jyväskylä.

Author Contributions J.H. carried out the synthetic and reaction studies, A.M. and P.V. carried out the computational analyses, J.H. conducted the crystallographic studies, J.H, J.M.G. and S.A. wrote the manuscript and J.M.G. and S.A managed the project.

Author Information X-ray crystallographic data for compounds 2, 3, 4 and 5 are freely available from the Cambridge Crystallographic Data Centre (CCDC 1854971-1854974). Reprints and permissions information is available at www.nature.com/reprints. The authors declare no competing financial interests. Correspondence and requests for materials should be addressed to S.A. (simon.aldridge@ @ chem.ox.ac.uk) or J.M.G. (jose.goicoechea@ chem.ox.ac.uk).

Competing financial interests The authors declare no competing financial interests. 


\section{Affiliations}

${ }^{1}$ Inorganic Chemistry Laboratory, Department of Chemistry, University of Oxford, South Parks Road, Oxford, UK OX1 3QR.

${ }^{2}$ Department of Chemistry, Nanoscience Center, University of Jyväskylä, P. O. Box 35, Jyväskylä, Finland FI-40014.

Jamie Hicks, ${ }^{1}$ Akseli Mansikkamäki, ${ }^{2}$ Petra Vasko, ${ }^{1,2}$ Jose M. Goicoechea*,1 and Simon Aldridge*,1

* To whom correspondence should be addressed. E-mail: simon.aldridge@ chem.ox.ac.uk (SA), jose.goicoechea@chem.ox.ac.uk (JMG) 


\section{Supplementary Information}

General considerations and starting material preparations; synthetic, spectroscopic and analytical

data; ${ }^{1} \mathrm{H}$ NMR spectra; X-ray crystallographic studies; computational studies and CIFs for all crystal structures. 